\title{
SONDAGEM GEOELÉTRICA USADA PARA INVESTIGAR O ESPAÇO DE ACOMODAÇÃO DOS SEDIMENTOS QUATERNÁRIOS NO ESTUÁRIO JACUÍPE, BAHIA, BRASIL
}

\author{
Geraldo Marcelo Pereira Lima ${ }^{1}$, Geraldo da Silva Vilas Boas² e Olivar Antônio Lima de Lima³ \\ Recebido em 20 agosto, 2010 / Aceito em 28 novembro, 2011 \\ Received on August 20, 2010 / Accepted on November 28, 2011
}

\begin{abstract}
This study has evaluated the sediment accommodation space of the Jacuípe estuary, located in the Camaçari county, northern coast of Bahia State, Brazil. Vertical electrical soundings were used to interpret the lithostratigraphic units underlaying the area. The studied environment is shown to be structurally controlled by the transition from the crystalline basement tectonic domain to that of the Recôncavo sub-basin. There are evidences, although incipients, that this control can drastically reduce the estuarine areas of accommodation, the opposite scenario reported in the literature. The soundings showed that the Quaternary sedimentary package of the estuary overlies directly the Recôncavo sub-basin, up to a maximum thickness of $20 \mathrm{~m}$ of sand. Accommodation volume spaces were determined for various estuarine scenarios, among them the total framework for the Holocene, of $6.84 \times 10^{7} \mathrm{~m}^{3}$ and the remaining smallest space $6.67 \times 10^{6} \mathrm{~m}^{3}$. The last value demonstrated the typical state of an environment in an advanced stage of infilling, with $9.89 \%$ of the initial volume.
\end{abstract}

Keywords: electroresistivity, accommodation space, estuaries.

RESUMO. 0 presente trabalho verificou o espaço de acomodação de sedimentos do estuário Jacuípe, localizado no município de Camaçari, no litoral norte da Bahia. A técnica de sondagem elétrica vertical foi usada para interpretar as unidades litoestratigráficas que preenchem a referida área. 0 ambiente estudado se mostra controlado estruturalmente pela transição dos domínios tectônicos do embasamento cristalino e da sub-bacia do Recôncavo. Há indícios, apesar de incipientes, de que esse controle possa afetar, dramaticamente, a redução do espaço de acomodação estuarino, cenário opostamente relatado na literatura. As sondagens elétricas verticais revelaram que os pacotes sedimentares quaternários do estuário recobrem diretamente a sub-bacia do Recôncavo, o maior deles possuindo espessura de $20 \mathrm{~m}$ de areia. Foram determinados os volumes dos espaços de acomodação para diversos cenários estuarinos, dentre eles 0 arcabouço total durante 0 Holoceno, de $6,84 \times 10^{7} \mathrm{~m}^{3}$ e 0 espaço restante, de $6,67 \times 10^{6} \mathrm{~m}^{3}$. Este último valor comprovou o estado típico de um ambiente em avançado estágio de preenchimento, com apenas 9,89\% do volume inicial.

Palavras-chave: eletrorresistividade, espaço de acomodação, estuários.

\footnotetext{
${ }^{1}$ Centro de Pesquisa em Geofísica e Geologia (CPGG), Universidade Federal da Bahia (UFBA), Instituto de Geociências, Rua Caetano Moura, 123, sala 116-D, Campus Ondina, 40170-290 Salvador, BA, Brasil. Tel.: (71) 3283-8515; Fax: (71) 3283-8501 - E-mail: glima@ufba.br

${ }^{2}$ Centro de Pesquisa em Geofísica e Geologia (CPGG), Universidade Federal da Bahia (UFBA), Instituto de Geociências, Departamento de Sedimentologia, Rua Caetano Moura, 123, Campus Ondina, 40170-290 Salvador, BA, Brasil. Tel.: (71) 3283-8604; Fax: (71) 3283-8501 - E-mail: gsvboas@ufba.br

${ }^{3}$ Centro de Pesquisa em Geofísica e Geologia (CPGG), Universidade Federal da Bahia (UFBA), Instituto de Geociências, Departamento de Geologia e Geofísica, Rua Caetano Moura, 123, Campus Ondina, 40170-290 Salvador, BA, Brasil. Tel.: (71) 3283-8597; Fax: (71) 3283-8501 - E-mail: olivar@cpgg.ufba.br
} 


\section{INTRODUÇÃo}

A aplicação de métodos geofísicos de alta resolução tem sido uma ferramenta essencial na reconstituição da arquitetura dos depósitos sedimentares costeiros em diversas partes do mundo (Porsani et al., 2004; Weschenfelder et al., 2008), principalmente para a caracterização dos processos de fundo e subfundo (Damuth \& Hayes, 1977; Damuth, 1980; Flood, 1980). Na costa atlântica sul-americana ( 12.500 km de extensão), os levantamentos geofísicos realizados restringem-se ao uso de sonares de varredura lateral e de sísmica rasa. No primeiro caso, existem trabalhos de caracterização das fácies sedimentares no estuário de Bahia Blanca, Argentina (Aliotta et al., 2004) e no Brasil, na baía de Guanabara, Rio de Janeiro (Baptista Neto et al., 1996; Quaresma et al., 2000) e na baía de Todos os Santos, Bahia (Lessa \& Dias, 2009). No segundo caso, Weschenfelder et al. (2008) mapearam na lagoa dos Patos (RS), por meio das discordâncias sismoestratigráficas, os pacotes e 0 truncamento das fácies sedimentares, além do espaço de acomodação da bacia marginal, com $-30 \mathrm{~m}$ de profundidade (2/3 deste verticalmente preenchidos), e a presença de paleocanais preenchidos durante as oscilações do nível marinho no Quaternário. Ambos os métodos mapearam apenas as áreas de superfície líquida dos ambientes, mas pouco se sabe sobre a condição evolutiva das dezenas de estuários brasileiros, com a descida do nível relativo do mar nos últimos 5.000 anos.

Estuários são ambientes formados pelo afogamento de um vale fluvial com a subida do nível relativo do mar (NRM), nos quais são criados espaços para acomodação de sedimentos fluviais e marinhos (Dalrymple et al., 1992). Geologicamente, os estuários são pouco duradouros e sua tendência evolutiva é serem gradualmente preenchidos até atingir um estágio final de evolução (em estágio regressivo) quando os sedimentos fluviais serão lançados diretamente no mar (Dalrymple et al., 1992). De modo geral, a maioria dos estuários brasileiros apresenta espaço de acomodação (espaço que permite 0 aumento de sedimentos) com reduzidas dimensões: opostamente a uma minoria deles, com profundidade de $-30 \mathrm{~m}$. Esta situação demonstra um avançado estágio de preenchimento sedimentar. Quanto maiores os espaços de acomodação são necessários maiores volumes de sedimentos e/ou maior tempo para seu preenchimento. Os diversos estuários que ainda se mantêm no litoral da Bahia, maior extensão de litoral do Brasil ( 1.000 km), possuem distintas características litológicas, geomorfológicas e sedimentológicas que enredam o entendimento do assunto.

Duas suposições foram inicialmente discutidas sobre as condições de preenchimento dos estuários brasileiros. A pri- meira suposição diz que o espaço de acomodação dos estuários, em especial, na baía de Todos os Santos, é afetado por eventos neotectônicos (movimentos crustais ocorridos desde 0 Neogeno até 0 Quaternário), tendo como consequência a subsidência do terreno e ampliação vertical da área de deposição (Martin et al., 1986). Neste caso, a ampliação dos espaços de acomodação se daria basicamente pela instalação de sistema de falhas planares. A segunda suposição argumenta que os espaços de acomodação foram gerados pela escavação fluvial, quando 0 nível de base estava vários metros abaixo do atual e, os estuários, não foram totalmente preenchidos devido ao reduzido suprimento de sedimento fluvial e, essa restrição, ocorre pela condição climática intermediária existente (nem úmida, nem árida) e pelo fato das bacias hidrográficas adjacentes possuírem pequenas áreas de drenagens (Dominguez et al., 2009).

Para avaliar 0 estágio evolutivo de preenchimento sedimentar descrito acima foi escolhido o estuário Jacuípe, localizado no litoral norte da Bahia, por ser um exemplo de ambiente fortemente controlado por estruturas tectônicas, formado na borda S-E da sub-bacia do Recôncavo em contato com o embasamento cristalino. Atualmente, essa área possui indicadores geomorfológicos (altimétricos e batimétricos), que aludem ao rebaixamento topográfico do vale fluvial (no baixo curso) e no estuário, onde 0 espaço de acomodação geralmente inferior a $-3 \mathrm{~m}$ são contraditos por depressões $-9 \mathrm{~m}$ abaixo do nível médio do mar (Lima, 2007). Os objetivos deste artigo são: (i) testar a aplicação de eletrorresistividade, como método geofísico utilizado para investigar a evolução e as condições de preenchimento de um estuário; (ii) analisar verticalmente a dimensão do espaço de acomodação a partir das espessuras dos pacotes sedimentares subjacente ao estuário; e (iii) observar se o mesmo é sustentado por algum tipo de controle estrutural neotectônico.

\section{ÁREA DE ESTUDO}

0 estuário Jacuípe encontra-se instalado na transição dos domínios tectônicos da bacia Recôncavo-Tucano-Jatobá (Cretáceo Inferior) e do embasamento cristalino (Pré-cambriano). Um sistema de falhas normais escalonadas pode ser percebido em superfície pela extensão das falhas de Salvador e do Iguatemi (Barbosa et al., 2005), com orientação NE-SW (Fig. 1). Ao se encontrarem no estuário, esse sistema de falhas muda para a direção N-S (aqui denominada falha do Jacuípe). Novamente os contornos da sub-bacia Recôncavo são desviados ao final da falha do Jacuípe, desta vez, pela falha Mata-Catú (Destro et al., 2003), com inflexão para NW-SE, formando um grande cotovelo 

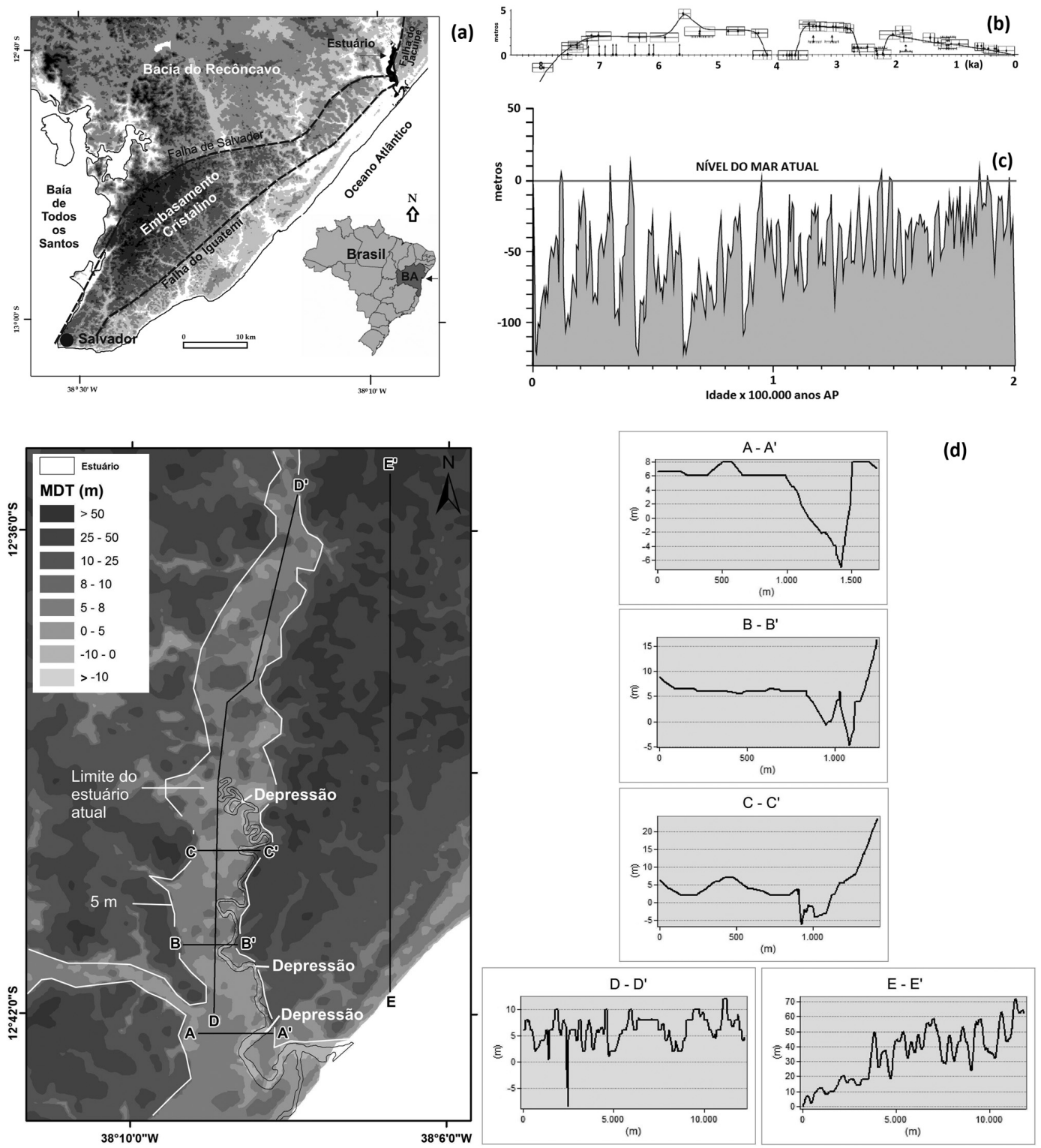

(d)



Figura 1 - Principais características do estuário Jacuípe. Em (a) o modelo digital de terreno (MDT) mostrando a transição da bacia sedimentar do Recôncavo com o embasamento cristalino; em (b) a curva das oscilações do NRM em Salvador, durante o Holoceno (Martin et al., 2003); em (c) as oscilações do NRM nos últimos 2 milhões de anos (Miller et al., 2005); em (d) a geomorfologia do estuário Jacuípe com perfis topográficos (A-A', B-B', C-C', D-D' e E-E') extraídos a partir de imagens SRTM; e em (e) e o perfil batimétrico longitudinal referente ao talvegue do estuário Jacuípe (Lima et al., 2011). As setas indicam as depressões mencionadas e sua localização no mapa acima. 
de borda de bacia, na qual funciona como divisor de águas entre a bacia hidrográfica do Jacuípe e a bacia circunvizinha do Pojuca. Tal sistema de falhas foi interpretado por Magnavita (1992), como decorrente de duas fases principais de movimento, ocorridas no Cretáceo Inferior. Na primeira fase, a zona de transferência da falha de Salvador teria ocorrido pela distensão E-W durante o Valengiano Superior (140.2 Ma \pm 3.0 ) e, na segunda fase, a subbacia teria sido rotacionada no sentido horário, formando uma zona strike-slip (Destro et al., 2003) no final da idade Barremiana (130.0 Ma \pm 1.5 ) onde hoje seria aproximadamente 0 estuário Jacuípe e a falha Mata-Catú, com orientação NW-SE.

Os afloramentos do embasamento cristalino são constituídos de rochas granulíticas (Paleoproterozoico) provenientes do Cinturão Salvador-Esplanada (Barbosa \& Dominguez, 1996). Na área de estudo, os afloramentos são discretos, encontrados na embocadura estuarina (vistos apenas na baixamar de sizígia) e a $2 \mathrm{~km}$ seguindo para montante. Na embocadura, o embasamento sustenta os depósitos quaternários e é responsável pela diminuição da profundidade do estuário, representando um alto estrutural (Alto de Salvador) e fazendo com que a altura da onda de maré seja amortizada, tornando esse ambiente de maré hiposincrônica (Lima, 2007).

A arquitetura básica da sub-bacia Recôncavo reflete as heterogeneidades do embasamento Pré-cambriano sobre o qual atuaram esforços distensionais durante 0 Cretáceo Inferior. Nesse período, a borda leste da bacia subsidiu rapidamente a $1.500 \mathrm{~m}$, assumindo um arcabouço tectônico de rifte assimétrico (Magnavita et al., 2005), resultando em uma bacia meio-gráben, cujo preenchimento foi finalizado pela sedimentação dos depósitos fluviais da Formação São Sebastião (Milani, 1987). Esta formação, localmente, é constituída de arenitos vermelhos e amarelos (Membro Rio Joanes), contendo intercalações de folhelhos e siltitos (Ghignone, 1979; Lima, 1999). No entorno do estuário, ambos os domínios supracitados são recobertos por depósitos residuais do Grupo Barreiras (Terciário Superior) e por depósitos arenosos da estreita planície costeira (Quaternário).

Segundo Vilas Boas et al. (2001), os depósitos do Grupo Barreiras encontrados ao longo do litoral norte da Bahia são interpretados como de origem predominantemente fluvial, de padrão entrelaçado, com carga de leito areno-cascalhosa, associados a leques aluviais depositados em condições de clima árido a semiárido.

Os depósitos quaternários mais antigos preservados no entorno do estuário Jacuípe são depósitos eólicos, com cerca de $25 \mathrm{~m}$ acima do nível do mar atual (Martin et al., 1980), tendo estes sido sucessores dos depósitos da Transgressão Mais
Antiga (Pleistoceno), constituídos de areia fina, quartzosa e bem selecionada.

Geologicamente, a presença de estuários na porção norte do litoral da Bahia deve ter sido restrita na maior parte do tempo, devido ao fato de se encontrar, naquela área, a menor extensão da plataforma continental do Brasil. Como fator agravante, soma-se o NRM ter permanecido durante 0 Quaternário, geralmente, em -45 m, ou seja, próximo à quebra da plataforma atual, sendo os sedimentos fluviais lançados diretamente no talude.

0 vale estuarino do Jacuípe é preenchido por areias que compõem os terraços marinhos derivados da Penúltima Transgressão pleistocênica (123 mil anos atrás), cerca de 5-8 m acima do nível atual (Martin et al., 1980; Martin et al., 1982; Bernart et al., 1983; Dominguez et al., 2009; Dominguez \& Bittencourt, 2009). Ainda no pleistoceno (19 mil anos atrás), o NRM rebaixou $-120 \mathrm{~m}$ e expôs toda a plataforma continental, bem como parte do arcabouço do estuário. 0 NRM voltou subir rapidamente durante 0 Holoceno (5 mil anos atrás), alcançando cerca de 3-4 m acima do nível atual (Martin et al., 2003; Dominguez et al., 2009) (Fig. 1). Desde então, o NRM vem descendo e, o estuário Jacuípe, gradualmente preenchido e o pequeno espaço de acomodação que resta é contrastado por três depressões encontradas no seu leito (Lima, 2007). As duas primeiras, localizadas a $4 \mathrm{~km}$ e 5,5 km da embocadura estão - $9 \mathrm{~m}$ abaixo do zero topográfico e, a última, situada a 13,7 km da embocadura, a -7,5 m (Fig. 2).

\section{MATERIAL E MÉTODOS \\ Sondagem elétrica vertical}

A eletrorresistividade foi o método elétrico utilizado para delinear 0 arcabouço do estuário Jacuípe, a espessura dos pacotes sedimentares e seus litotipos. A técnica aplicada foi a sondagem elétrica vertical (SEV). Esta técnica determina o comportamento do fluxo de corrente elétrica em solos, sedimentos e rochas, com 0 objetivo de determinar a variação da resistividade elétrica de acordo com a profundidade (Cavalcanti, 2006). A resistividade elétrica das rochas é controlada basicamente pela textura (porosidade e permeabilidade) e pela natureza dos fluídos intersticiais.

0 arranjo utilizado na execução da sondagem elétrica vertical foi o de Schlumberger, que consiste basicamente no uso de medidas da corrente elétrica injetada entre dois pontos no terreno ( $\mathrm{A}$ e $\mathrm{B})$ e da diferença de potencial entre dois outros pontos $(\mathrm{M}$ e N). Ao expandir os eletrodos, a corrente elétrica penetra mais profundamente no substrato permitindo a investigação das camadas mais inferiores. Neste caso, as aberturas de $\mathrm{AB} / 2$ variaram de $1,0 \mathrm{~m}$ até $200 \mathrm{~m}$. 


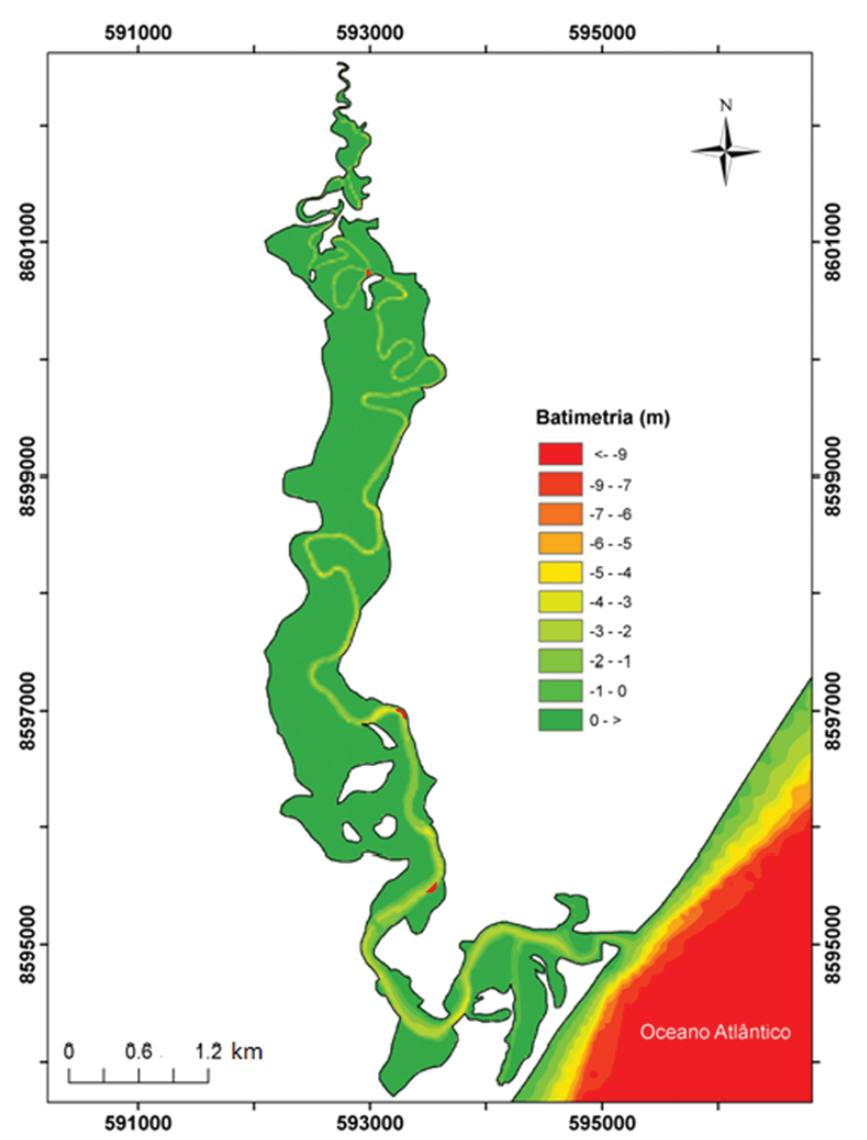

Figura 2 - Mapa batimétrico do estuário Jacuípe (Lima, 2007; Lima et al., 2011).

Geralmente, utiliza-se SEVs ao longo de um perfil para caracterizar uma seção geoelétrica, as quais correspondem às distribuições verticais das resistividades dentro de um volume determinado do subsolo. As camadas obtidas, com seus valores de resistividade e espessura, constituem os níveis geoelétricos que, por sua vez, são correlacionados com os litotipos da área estudada.

Quatro sondagens elétricas verticais (SE-1, SE-2, SE-3 e SE-4) foram realizadas em junho de 2010, tendo os pontos de sondagens sidos previamente escolhidos com base em fotografias aéreas, de modo a se obter um perfil geológico cortando os domínios entre a bacia do Recôncavo e o embasamento cristalino, no trecho estuarino onde se encontram as maiores depressões (0 equivalente ao perfil A-A', ver Fig. 1). A resistência de contato nos eletrodos foi minimizada com 0 uso de água salgada, especialmente na seção SE-4.

0 equipamento usado para coletar os dados foi um eletrorresistivímetro SYSCAL-R2 com potência máxima de 250 W. 0 centro das sondagens foi nivelado à topografia local, utilizando- se as folhas do Sistema Cartográfico da Região Metropolitana de Salvador - SICAR-RMS (CONDER, 1976), em escala de detalhe de 1:10.000 (Fig. 3) e os dados batimétricos utilizados foram realizados por Lima (2007).

A interpretação dos dados de eletrorresistividade, em modelos de camadas horizontais, é feita pelo procedimento de inversão. Utilizou-se o programa RES1D para inverter os dados de eletrorresistividade, refinando automaticamente o modelo inicial para um modelo de melhor ajuste em cinco camadas. Primeiramente, obteve-se um modelo inicial, por meio da técnica da superposição parcial. Estes parâmetros iniciais são fornecidos ao processo de inversão automática. Após a inversão, os parâmetros finais resultantes são usados para computar a curva teórica do modelo de melhor ajuste aos dados experimentais. 0 procedimento consiste em calcular os parâmetros (resistividades e espessuras) de um dado modelo constituído de camadas horizontais isotrópicas e homogêneas, a partir de valores de resistividade aparente medidos para diferentes espaçamentos. 


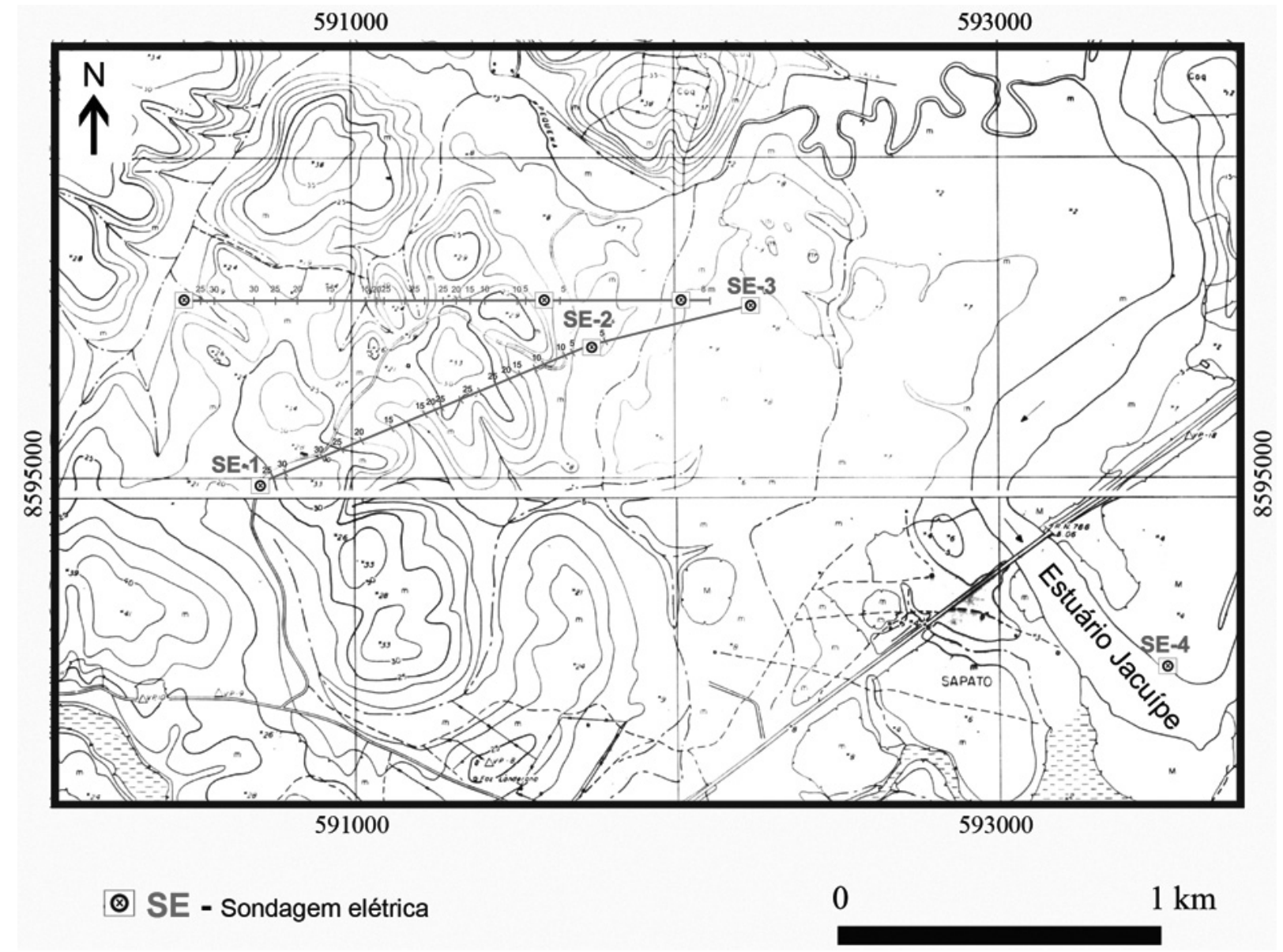

Figura 3 - Dados topográficos dos pontos de sondagens realizados na planície costeira adjacente ao estuário Jacuípe, obtidos a partir das folhas do SICAR-RMS, em escala de detalhe de 1:10.000.

Com base nos valores de espessuras e resistividades das camadas encontradas no substrato, as unidades litoestratigráficas que preenchem 0 estuário puderam ser interpretadas pelas propriedades elétricas conhecidas nas rochas (Lima \& Sharma, 1990) e por trabalhos realizados na região (Lima, 1999; Santos, 2003; Cavalcanti, 2006).

\section{RESULTADOS}

0 resultado das sondagens elétricas verticais mostra, transversalmente, a transição entre 0 embasamento cristalino e a bacia do Recôncavo, no qual 0 vale estuarino encontra-se instalado (Figs. 4 e 5).

A sondagem SE-1 (localizada a oeste) é a topograficamente mais elevada, com $22 \mathrm{~m}$. Nessa sondagem, a camada superficial, de espessura de 4,4 m e resistividade variando entre $698 \mathrm{ohm} . \mathrm{m}$ e 108 ohm.m é interpretada como um pacote de areia inconsolidada, associada aos depósitos eólicos quaternários mais antigos
(Pleistoceno). A variação de resistividade nessa camada inicial se relaciona com a presença de água na parte inferior. Logo abaixo, observa-se uma camada com resistividade de 2.030 ohm.m e com aproximadamente $9 \mathrm{~m}$ de espessura, associada ao Grupo Barreiras (Terciário), cujo nível de base está a $9 \mathrm{~m}$ acima do zero topográfico. Imediatamente abaixo do Grupo Barreiras ocorrem duas camadas com resistividades de 667 ohm.m e 30 ohm.m, interpretadas como arenitos e folhelhos da Formação São Sebastião, respectivamente (sub-bacia do Recôncavo).

A sondagem SE-2 apresenta a mesma sequência estratigráfica da sondagem anterior, constituída do topo para base, de areias correspondente aos terraços marinhos pleistocênico, com diferença apenas nas espessuras das camadas e na topografia mais baixa (altitude de $4 \mathrm{~m}$ ). Os depósitos do Grupo Barreiras apresentaram menor resistividade e espessura da camada, de 1048 ohm.m e 3,8 m, respectivamente. A diferença na resistividade elétrica observada no Grupo Barreiras entre as SEVs 1 e 2 é atribuída à variação granulométrica e ao conteúdo de 
(a)

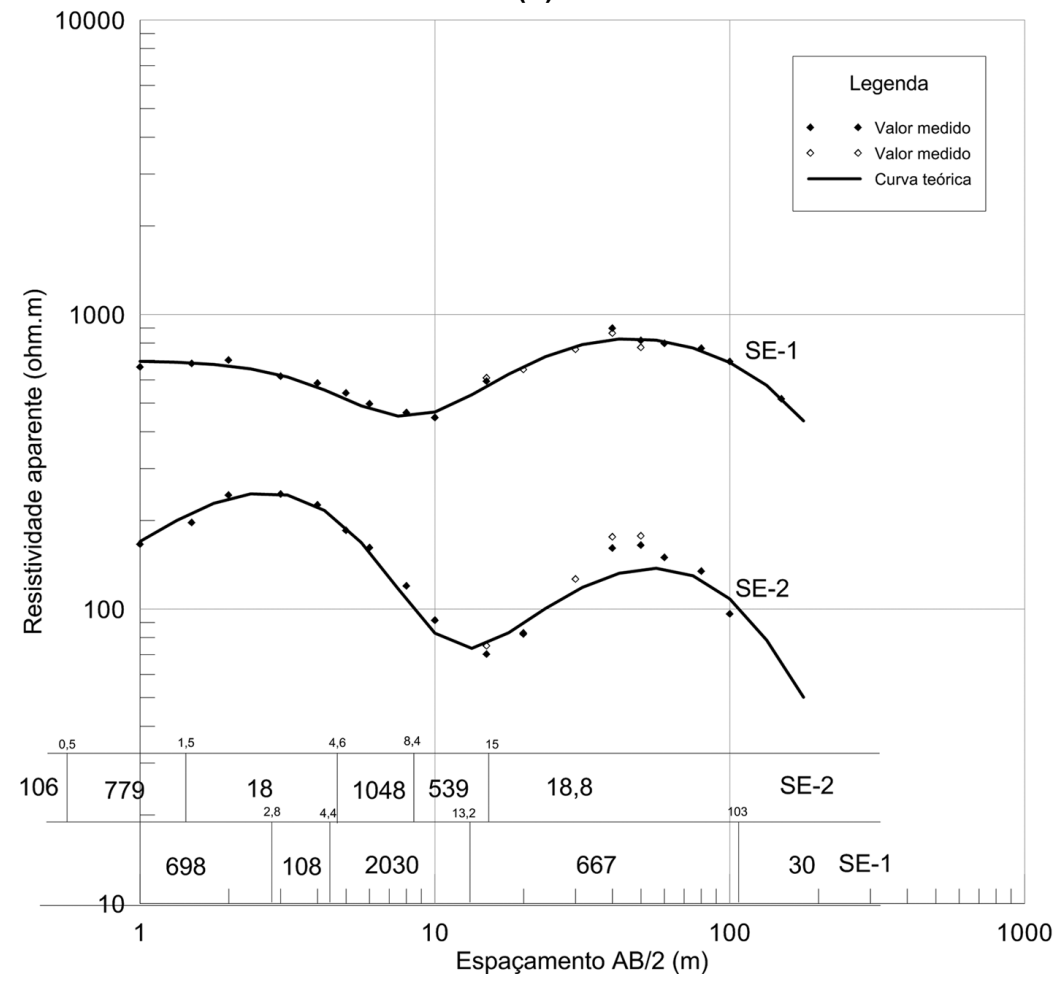

(b)

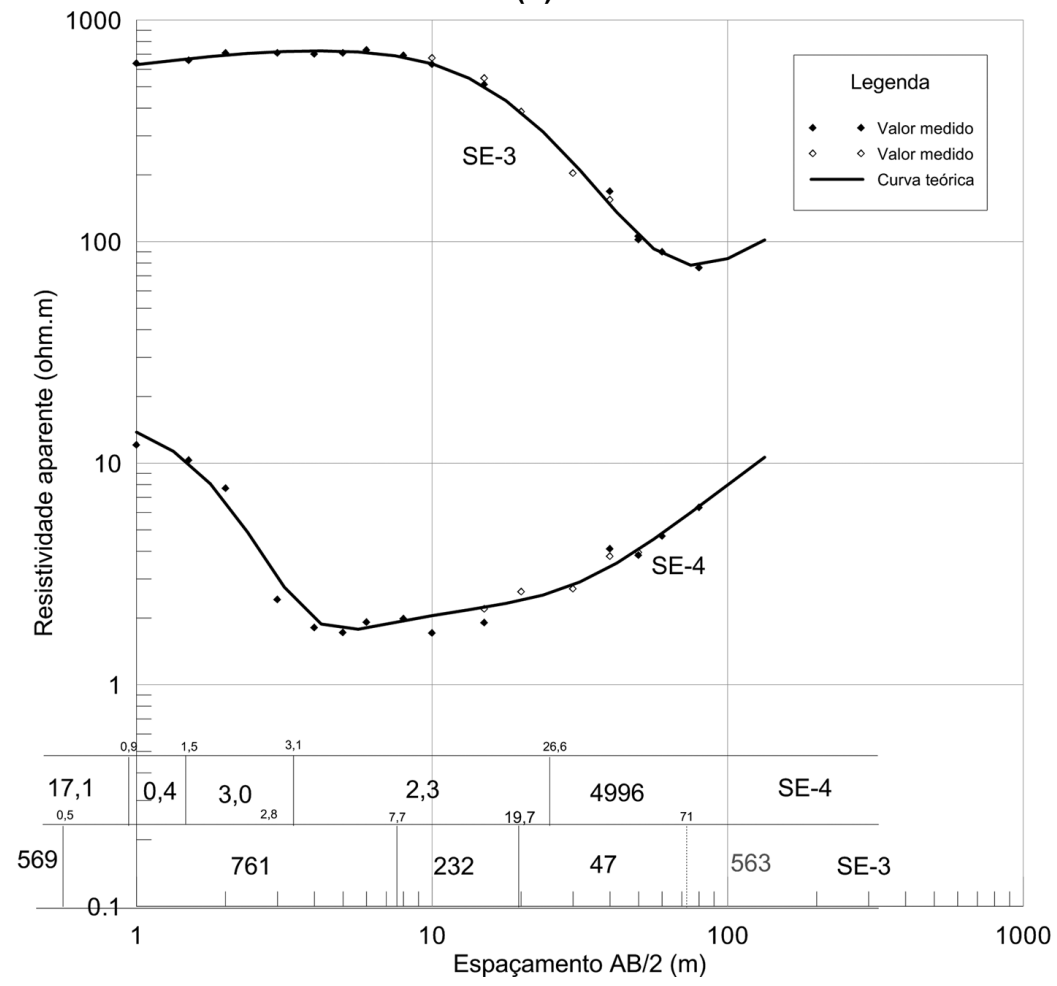

Figura 4 - Sondagens elétricas verticais realizadas na borda da bacia do Recôncavo, onde se encontra instalado o estuário Jacuípe. Em (a) refere-se às SE-1 e SE-2 e em (b) às SE-3 e SE-4. 



Figura 5 - Perfil geológico A-A' interpretado a partir das sondagens elétricas realizadas no estuário Jacuípe. A linha tracejada na imagem acima se refere aos alinhamentos estruturais inferidos e, na figura abaixo, ao zero topográfico atual. 
argila. Pode-se também observar que a base do Grupo Barreiras na SE-2 encontra-se desnivelada cerca de 13,4 m abaixo se comparado à seção SE-1 e não aparece na SE-3. 0 local da sondagem SE-2 representa o limite lateral de escavação do paleoestuário durante 0 Quaternário.

A sondagem SE-3 apresenta três camadas com resistividade variando entre 569 ohm.m, 761 ohm.m e 232 ohm.m, representando areias pleistocênicas uma vez que o topo encontra-se a uma altitude de $8 \mathrm{~m}$. 0 arcabouço do paleoestuário nessa sondagem representa 0 maior espaço de acomodação do perfil realizado, com aproximadamente $20 \mathrm{~m}$, é preenchido por areia, sendo que atualmente $12 \mathrm{~m}$ deste encontra-se abaixo do zero topográfico (Fig. 4). A Formação São Sebastião está presente em todas as sondagens, funcionando como alicerce do estuário, exceto na sondagem SE-4.

A sondagem SE-4 mostra depósitos arenosos holocênicos na superfície, com espessura de 3,1 m, cuja resistividade baixa varia de 17,1 ohm.m a 3,0 ohm.m, se deve pela presença de água salgada, por estar situada na margem do estuário. Este depósito recobre diretamente 0 embasamento cristalino. A parte superior do embasamento apresenta 23,5 m de espessura e resistividade de 2,3 ohm.m, com características de bastante alterado (saprólito). A partir da profundidade de $26 \mathrm{~m}, 0$ embasamento apresenta resistividade de 4996 ohm.m, devido à presença de água doce nos seus interstícios (Fig. 4).

0 perfil geológico construído a partir das SEVs, da topografia do terreno e dos depósitos sedimentares (Fig. 5), foi extrapolado pela linha de sondagens SE-1, SE-2 e SE-3 até a outra margem do estuário. Observou-se que a escavação do leito estuarino do Jacuípe atingiu uma profundidade $-12 \mathrm{~m}$ abaixo do zero topográfico atual e uma extensão lateral máxima de 1,2 km.

Com base nas interpretações das sondagens elétricas verticais no estuário Jacuípe e nas observações em campo, podem ser mencionadas as seguintes evidências a comprovar o controle estrutural de uma área de transição litológica:

- Desnivelamento da sub-bacia do Recôncavo em relação ao embasamento cristalino (Fig. 5). As rochas sedimentares da Formação São Sebastião que finalizaram o preenchimento desta bacia, estão, atualmente, topograficamente mais elevadas que o embasamento;

- Desnivelamento da base do Grupo Barreiras entre as sondagens SE-1 e SE-2, em 13,5 m (Fig. 5), podendo ser consequência da primeira evidência citada;

- Alargamento abrupto da planície de inundação no km 4 a partir da embocadura, a contramargem da falha do
Jacuípe, coincidindo com a primeira depressão já enunciada anteriormente. Esse alargamento se estende de forma retilínea e alinhada com 0 vale encaixado do rio Capivara Pequeno (Fig. 5);

- Área de estudo é marcada por fortes traços estruturais gerados pela influência do sistema de falhas que convergem para 0 estuário, gerando contornos retilíneos e interceptados por curvaturas com ângulos de aproximadamente 90 (Fig. 1a);

- Área de estudo possui antecedentes de subsidência em seus substratos antigos.

Com base nas SEVs pode-se reconstituir os volumes correspondentes ao espaço de acomodação no paleoestuário Eq. (1), obtidos pela seguinte relação:

$$
V=h \cdot A
$$

onde, $V$ é 0 volume do espaço de acomodação $\left(\mathrm{m}^{3}\right)$ estimado para cada posição do NRM, $h$ é a profundidade máxima (m) do arcabouço estuarino desprovido de sedimentos, nivelado em relação ao zero topográfico atual e, $A$ é a área $\left(\mathrm{m}^{2}\right)$ inundada durante a transgressão marinha (assumida como a cota de $5 \mathrm{~m}$ ) e atual. Um resumo das características volumétricas e sedimentológicas para diversos cenários do estuário Jacuípe podem ser observados na Tabela 1.

0 volume máximo para acomodação dos sedimentos nesse estuário é de $6,84 \times 10^{7} \mathrm{~m}^{3}$, cenário este, idealizado com 0 arcabouço estuarino nu (espaço entre a Formação São Sebastião e o NRM cerca de $5 \mathrm{~m}$ acima do atual). De acordo com as SEVs e com os dados batimétricos obtidos por Lima et al. (2011) resta, ao estuário Jacuípe, um volume total de $6,77 \times 10^{6} \mathrm{~m}^{3}$ (espaço referente ao prisma de sizígia mais 0 espaço inframareal) e, esse valor, corresponde a 9,89\% do volume original do estuário, 0 que comprova o seu avançado estágio de preenchimento. Este espaço de acomodação restante ao estuário Jacuípe é imensamente menor se comparado ao da baía de Todos os Santos (segunda maior baía em área do Brasil, $\sim 1200 \mathrm{~km}^{2}$ ), com volume de $12,5 \times 10^{9} \mathrm{~m}^{3}$, onde $3,36 \times 10^{9} \mathrm{~m}^{3}$ correspondem apenas à zona intermareal de sizígia (Lima \& Lessa, 2001).

A possibilidade de incorrer em erro nesta reconstituição seria se: entre a SE-3 e a margem interna do estuário (planície de inundação intermareal), local onde não foi possível se obter outras sondagens estiver com valores subestimados, se ali ocorrer 0 talvegue preenchido, mais profundo que 0 aqui observado (proporcional ao que se simboliza a depressão atual). As sondagens elétricas verticais não puderam ser realizadas naquela 
Tabela 1 - Resumo das principais características hidrológicas, sedimentológicas e geomorfológicas do estuário Jacuípe.

\begin{tabular}{|c|c|c|c|}
\hline & Ambiente & Valores & Observações \\
\hline Área $\left(\mathrm{km}^{2}\right)$ & $\begin{array}{l}\text { Bacia hidrográfica } \\
\text { Estuário atual } \\
\text { Estuário holoceno }\end{array}$ & $\begin{array}{l}1275 \\
6,22 \\
17,0\end{array}$ & $\begin{array}{l}\text { Imagens SRTM resolução de } 30 \text { m } \\
\text { Folhas topográficas 1:10.000 } \\
\text { Imagens SRTM resolução de } 30 \text { m }\end{array}$ \\
\hline $\begin{array}{c}\text { Taxa de } \\
\text { sedimentação }(\omega) \\
\left(\mathrm{mm} \mathrm{ano}^{-1}\right)\end{array}$ & $\begin{array}{l}1870-1965 \\
1965-2008\end{array}$ & $\begin{array}{l}3,7 \\
6,0\end{array}$ & Lima et al. (2011) \\
\hline $\begin{array}{l}\text { Taxa descida do } \\
\text { NRM (mm ano-1) }\end{array}$ & $\begin{array}{c}1000 \text { mil anos } \\
\text { antes do presente }\end{array}$ & 1,2 & $\begin{array}{l}\text { Valor estimado pela curva de } \\
\text { Salvador (Martin et al., 2003) }\end{array}$ \\
\hline $\begin{array}{l}\text { Espaço de } \\
\text { acomodação } \\
\text { estuarino } \\
\left(\mathrm{m}^{3}\right)\end{array}$ & $\begin{array}{c}\text { Inframareal } \\
\text { Intermareal } \\
\text { Arcabouço nu } \\
\text { Arcabouço total }\end{array}$ & $\begin{array}{l}1,96 \times 10^{6} \\
4,80 \times 10^{6} \\
2,04 \times 10^{7} \\
6,84 \times 10^{7}\end{array}$ & $\begin{array}{l}\text { Volume abaixo do nível de redução } \\
\text { Prisma de maré de sizígia } \\
\text { Volume entre as cotas }-12 \mathrm{~m} \text { e } 0 \mathrm{~m} \text { * } \\
\text { Volume entre as cotas }-12 \mathrm{~m} \text { e } 5 \mathrm{~m}^{*}\end{array}$ \\
\hline $\begin{array}{l}\text { Estimativa do tempo } \\
\text { necessário para o } \\
\text { preenchimento (ka) }\end{array}$ & $\begin{array}{c}0-5 \mathrm{~m} \\
\text { Perfil A-A' } \\
\text { Total }\end{array}$ & $\begin{array}{c}7,6 \\
3,2 \\
10,8\end{array}$ & $\begin{array}{l}\text { Taxa de sedimentação } \\
\text { de } 3,7 \mathrm{~mm} \text { ano }^{-1}\end{array}$ \\
\hline $\begin{array}{l}\text { Espessura do pacote } \\
\text { sedimentar (m) }\end{array}$ & $\begin{array}{c}\text { Idade } \\
\text { Pleistocênica }\end{array}$ & 20 & SE-03 (este trabalho) \\
\hline $\begin{array}{l}\text { Profundidade } \\
\text { atual (m) }\end{array}$ & $\begin{array}{l}\text { Média } \\
\text { Máxima }\end{array}$ & $\begin{array}{l}1,5 \\
9,0\end{array}$ & Lima et al. (2011) \\
\hline
\end{tabular}

${ }^{*}$ correspondente à área total inundada pelo nível marinho até a cota de $5 \mathrm{~m}\left(17 \mathrm{~km}^{2}\right)$. ${ }^{* * i d e m}$.

área, por esta ser coberta pela vegetação de mangue, de difícil acesso e locomoção e pela presença de água salobra percolada no substrato, o que dificultaria a leitura pelo equipamento.

Com os volumes conhecidos do espaço de acomodação, pode-se checar o tempo suficiente e/ou volume de sedimento necessário para preencher o estuário Jacuípe, comparando-os com as taxas de sedimentação e de descida do NRM (Tab. 1). As únicas taxas de sedimentação disponíveis no estuário são consideradas como alta (Lima et al., 2011). A taxa de sedimentação de 3,7 mm ano-1 (1870-1965) demonstra que a capacidade de preenchê-lo totalmente ocorreria em 10,8 mil anos. Isto representa, pelo menos, $10 \%$ da idade dos depósitos mais antigos preservado no vale estuarino antigo. 0 valor mencionado, inclusive, quase dobrou desde 1965 até o presente $\left(6,0 \mathrm{~mm}^{2} \mathrm{ano}^{-1}\right)$. Se o NRM tivesse permanecido estável a cerca de 5.000 anos atrás, seria necessária apenas uma taxa de sedimentação de 2,3 $\mathrm{mm}_{\text {ano }}{ }^{-1}$ para preencher 0 arcabouço estuarino. Estas estimativas apresentadas, apesar de incipientes, pois as taxas de sedimentação estuarina não devem ter sido contínuas no tempo, tampouco 0 arcabouço estuarino deve ter uma morfologia uniforme até a cabeceira, demonstram que 0 suprimento de sedimento produzido pela bacia é suficiente para preencher o estuário.

\section{DISCUSSÃO}

A sondagem elétrica vertical mostrou-se um método geofísico eficiente para avaliar paleovales estuarinos preenchidos e seus substratos. No entanto, não há registro de trabalhos realizados no Brasil e no mundo que avaliassem em que estágio final de preenchimento encontram-se os estuários quanto a espaço de acomodação dos sedimentos (volumes iniciais e atuais). Os locais que oferecem esses tipos de dados possuem grandes extensões, de modo que, comparações análogas serão possíveis apenas do ponto de vista das espessuras dos pacotes sedimentares.

Sondagens elétricas verticais realizadas na proximidade do estuário Jacuípe, da linha de costa para 0 continente (Santos, 2003) e uma seção sísmica no mesmo sentido (Milani, 1987) corroboram de forma preliminar que um forte controle estrutural é exercido pelo contato do embasamento com a sub-bacia (Fig. 6). 

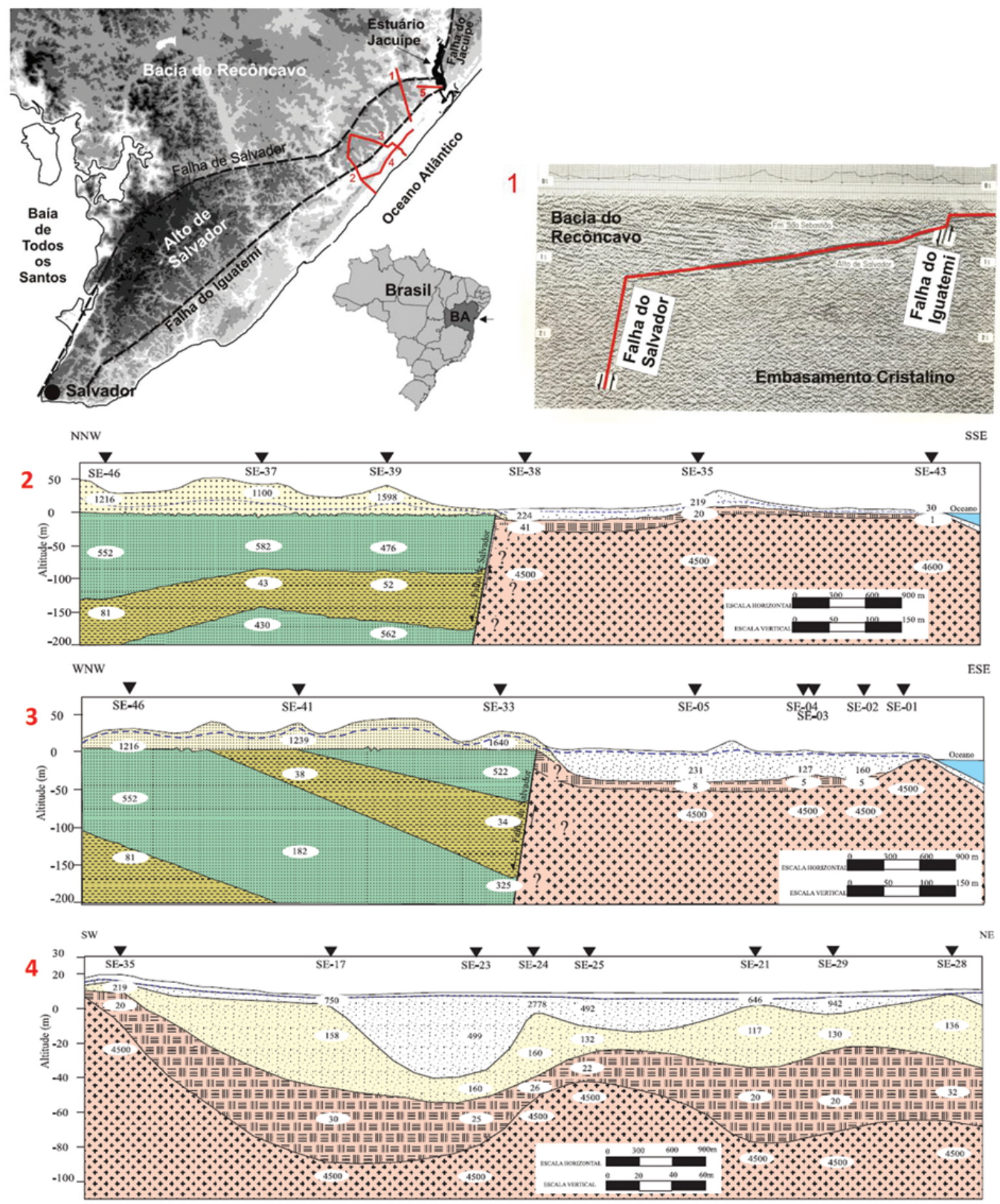

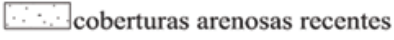

:::: sedimentos inconsolidados (areias e cascalhos)


sedimentos consolidados condutivos (argilas)

\section{nível piezométrico}

4500 Resistividade (Ohm.m)

$\equiv$ Em

$++_{++}^{++}$rocha cristalina sã

Figura 6 - Espaços para acomodação de sedimentos verificados a partir de sondagens elétricas verticais e um perfil sísmico na borda da bacia do Recôncavo. Em 1, observa-se a extensão das falhas de Salvador e do Iguatemi (Milani, 1987; Barbosa et al., 2005), em 2, 3 e 4 (Santos, 2003) e em 5 este trabalho (ver Fig. 5). 
Uma semelhança conferida em todos os perfis é de que a subbacia do Recôncavo se encontra mais elevada topograficamente que o embasamento cristalino. Ao contrário do estuário Jacuípe, 0 maior espaço de acomodação está presente sobre o embasamento cristalino, onde acumulam o dobro da espessura em areias quaternárias (Perfil 3 - Fig. 6). Localmente, a proeminência da bacia impediu a ampliação da planície costeira durante as transgressões ao truncar os depósitos quaternários. Ainda neste litoral, sondagens elétricas realizadas mais a norte, no rio Itapicuru (a margem da BA-099), demonstraram um vale inciso profundo (com mais de $300 \mathrm{~m}$ ), instalado em uma área com fortes traços estruturais do embasamento cristalino e preenchido por depósitos do Grupo Barreiras (Costa Júnior, 2008).

No litoral sul da Bahia, a suposição de neotectonismo é personificada por diversos vales rebaixados, vistos desde 0 trecho estuarino e prosseguem por vários quilômetros na direção do vale fluvial, dentre eles os rios: Buranhém, João de Tiba, dos Frades e Jucuruçu, contendo falhas normais com hachuras no bloco de baixo (CBPM, 2000), sendo cogitada a ocorrência dos eventos neotectônicos, pós-deposicional ao Grupo Barreiras (Lima et al., 2006).

Dominguez \& Bittencourt (2009) avaliaram as linhas sísmicas de alta resolução realizadas na baía de Todos os Santos (porção sul da sub-bacia do Recôncavo). Suas interpretações não mencionam qualquer evidência de movimentações neotectônicas subsidentes, responsáveis pela criação dos espaços de acomodação. A morfologia dessa baía teria sido rebaixada pelo processo de erosão diferencial atuante, preferencialmente, nas rochas sedimentares da sub-bacia do Recôncavo, durante 0 Cenozoico, quando o nível de base se encontrava vários metros abaixo do atual.

Da mesma forma, o fato da bacia Recôncavo-Tucano-Jatobá encontrar-se topograficamente mais elevada que 0 embasamento cristalino pode ser mais um contra-argumento aos episódios de subsidência tectônica. Tal fenômeno se deve por episódios de soerguimento da região a partir do Eoceno (40 Ma) e se mantém no presente (Turner et al., 2008). Na parte central da sub-bacia do Recôncavo, a exumação das rochas sedimentares e a erosão atingiram verticalmente cerca de $1 \mathrm{~km}$ desde 0 início do evento. Vale ressaltar que a exumação da bacia Recôncavo-Tucano-Jatobá é ubíqua (simultânea em locais diferentes) as demais bacias sedimentares do NE brasileiro (Morais Neto et al., 2006; Turner et al., 2008). Em ambos os casos, o desnível topográfico das bacias pode ultrapassar $600 \mathrm{~m}$ acima do embasamento.

As condições de soerguimento continental devem afetar duplamente os estuários. Primeiramente, conforme observado no estuário Jacuípe, a parte da bacia por estar mais elevada que 0 embasamento deve ter proporcionado a diminuição do espaço de acomodação dos sedimentos (fenômeno não antes mencionado pela literatura). Secundariamente, o processo de soerguimento geralmente ocasiona aumento na produção de sedimentos pela bacia hidrográfica e, por conseguinte, acelera o preenchimento do estuário. 0 fenômeno do soerguimento na bacia Recôncavo-Tucano-Jatobá é também confortável para explicar o porquê de uma bacia hidrográfica relativamente pequena, como é o caso do rio Jacuípe $\left(1275 \mathrm{~km}^{2}\right)$, contribui com um aporte sedimentar tão alto para o estuário, de 3,7 $\mathrm{mm}$ ano-1 (entre 1860 e 1960) se comparada de forma proporcional a outros ambientes no Brasil e no mundo (Lima et al., 2011). Este valor é, inclusive, o triplo da taxa de descida do NRM, de $1,2 \mathrm{~mm}$ ano ${ }^{-1}$, observada pela curva de Salvador nos últimos 1.000 anos (Martin et al., 2003).

No que tange as depressões enunciadas neste trabalho (ver Fig. 1), até então não havendo evidências de déficit sedimentológico e nem sinais subsidência do estuário, as mesmas podem ser explicadas por coincidirem com as margens côncavas dos meandros, estando aptas a ser erodidas e/ou por não permitirem que 0 sedimento se deposite. Prova disso, se dá pela depressão a montante ter sido derivada do desvio do curso do rio e pelo abandono do meandro, devido às bruscas intervenções hidrológicas ocorridas na década de 1980 (Lima et al., 2011).

Neste trabalho não foram evidenciados concretamente que os espaços de acomodação no estuário Jacuípe tenham correlação com neotectonismo. Assume-se apenas que: a origem do estuário se deu a partir da incisão fluvial no ponto de fraqueza do contato litológico (por erosão diferencial) entre bacia e embasamento. 0 recuo das vertentes alargou 0 vale fluvial e expôs, no seu leito, as rochas da sub-bacia do Recôncavo. 0 vale fluvial se alargou cerca de 1,2 e $2 \mathrm{~km}$, expondo na sua margem esquerda a escarpa de falha do embasamento e, na outra margem, os depósitos do Grupo Barreiras. Nestas condições, a imprecisão estaria apenas relacionada quanto à posição da desembocadura por conta da presença do embasamento cristalino. Presume-se que a mesma ocorria mais para sul. Posteriormente, a inundação do vale fluvial com a subida do nível do mar, formara-se um estuário raso, o qual foi sendo preenchido por sedimentos fluviais e marinhos.

Em suma, a discussão sobre 0 aumento/redução do espaço de acomodação em estuários é ainda embrionária, fazendo-se necessários estudos mais aprofundados (geofísicos, estruturais e sedimentológicos) que confirmem ou não as condições de neotectonismo. 


\section{CONCLUSÕES}

Com base nos dados obtidos com a sondagem elétrica vertical no estuário Jacuípe, localizado no litoral norte da Bahia, e comparados com as informações da literatura pertinente, pode-se concluir que:

- A sondagem elétrica vertical se mostrou um método geofísico eficaz para avaliar as condições de evolução do espaço de acomodação sedimentar de um estuário.

- Ainda com base na sondagem elétrica vertical, o estuário Jacuípe se mostra um ambiente controlado por estruturas tectônicas, refletindo os substratos antigos preexistentes do embasamento cristalino e da sub-bacia do Recôncavo, nesta última, sobre o qual o estuário encontra-se preferencialmente instalado.

- A sondagem elétrica vertical combinada ao método de ecobatimetria demonstra o estuário Jacuípe como um ambiente em avançado estágio de preenchimento sedimentar, uma vez que, cerca de 90\% do espaço de acomodação, originados durante 0 Quaternário, já foram ocupados.

- 0 espaço de acomodação dos sedimentos obtidos com mapas topográficos e sondagens elétricas verticais demonstra que o estuário primitivo possuía profundidades de $-12 \mathrm{~m}$ (abaixo do NRM atual) e largura de 1,2 km (atualmente com $200 \mathrm{~m}$ ).

- Na parte da bacia, a coluna estratigráfica, quando não há discordância, é composta por folhelhos e arenitos da Formação São Sebastião (máximo de $80 \mathrm{~m}$ abaixo do zero topográfico), na qual é coberto por depósitos residuais do Grupo Barreiras e ao topo pelos depósitos Quaternários, cujo pacote de sedimentos alcança $20 \mathrm{~m}$. Fora da bacia, os sedimentos holocênicos ocorrem diretamente sobre o embasamento cristalino e não ultrapassam 3 m de espessura.

- Os resultados obtidos com as sondagens elétricas verticais são capazes de fornecer indícios neotectônicos, uma vez que, todas as bacias citadas no NE brasileiro vêm sofrendo reativação desde o Cenozoico e, com isso, ampliase a discussão sobre o espaço de acomodação para deposição de sedimentos em estuários.

\section{AGRADECIMENTOS}

Ao Centro de Pesquisa em Geofísica e Geologia - CPGG, pelos equipamentos cedidos e pela logística designada para a realização das sondagens elétricas verticais.

\section{REFERÊNCIAS}

ALIOTTA S, LIZASOAIN GO \& GINSBERG SS. 2004. Dinámica sedimentaria y evolución morfológica de un profundo canal del estuario de Bahía Blanca. Revista de la Asociación Geológica Argentina, 59(1): 14-28.

BAPTISTA NETO JA, DA SILVA MAM \& FIGUEIREDO JR AG. 1996. Sísmica de alta frequência e o padrão de distribuição de sedimentos na enseada de Jurujuba (Baía de Guanabara)-RJ/Brasil. Revista Brasileira Geofísica, 14(1): 51-57.

BARBOSA JSF \& DOMINGUEZ JML. 1996. Geologia da Bahia: texto explicativo para o mapa geológico ao milionésimo. Salvador, Secretaria da Indústria, Comércio e Mineração, SGM, 400 p.

BARBOSA JSF, CORRÊA-GOMES LC, DOMINGUEZ JML, CRUZ SAS \& SOUZA JS. 2005. Petrografia e litogeoquímica das rochas da parte oeste do alto de Salvador, Bahia. Revista Brasileira de Geociências, 35: 9-22.

BERNART MS, MARTIN L, BITTENCOURT ACSP \& VILAS BOAS GS. 1983. Datations I0-U du plus haut niveau marin du dernier interglaciaire sur la côte du Brésil. Utilisation du ${ }^{229}$ Th comme traceur. C.R. Acad. Sc. Paris, 296: 198-199.

CAVALCANTI SS. 2006. Quantificação dos recursos hídricos subterrâneos do aquífero recôncavo na bacia do rio Capivara. Tese de Doutorado em Geofísica. Instituto de Geociências, Universidade Federal da Bahia. Salvador - Bahia, $121 \mathrm{p}$.

CBPM (Companhia Baiana de Pesquisa Mineral). 2000. Projeto Costa do Descobrimento - Programa de Avaliação de Potencialidades Minerais - PAPM, CBPM. CD-ROM.

CONDER. 1976. Sistema Cartográfico da Região Metropolitana de Salvador - SICAR-RMS: Folhas topográficas 101000, 089000, 076000, 063000. Escala 1:10.000.

COSTA JÚNIOR MPC. 2008. Interações morfo-pedogenéticas nos sedimentos do grupo Barreiras e nos leques aluviais pleistocênicos no litoral norte do estado da Bahia - município de Conde. Tese de Doutorado em Geologia. Instituto de Geociências, Universidade Federal da Bahia. Salvador - Bahia, $246 \mathrm{p}$.

DALRYMPLE RW, ZAITLIN BA \& BOYD R. 1992. Estuarine Facies Models: Conceptual Basis and Stratigraphic Implications. J. Sedim. Petrol., 62: 1130-1146.

DAMUTH JE. 1980. Use of high-frequency (3.5-12 kHz) echograms in the study of near-bottom sedimentation processes in the deep sea: A review. Mar. Geol., 38: 51-75.

DAMUTH JE \& HAYES DE. 1977. Echo character of the East Brazilian Continental Margin and its relationship to sedimentary processes. Mar. Geol., 24: 73-95.

DESTRO N, SZATMARI P, ALKMIM FF \& MAGNAVITA LP. 2003. Release faults, associated structures, and their control on petroleum trends in the Recôncavo rift, northeast Brazil. AAPG Bull., 7: 1123-1144. 
DOMINGUEZ JML \& BITTENCOURT ACSP. 2009. Geologia. In: HATJE $V$ \& ANDRADE JB. (Org.). Baía de Todos os Santos: Aspectos oceanográficos. Salvador: Edufba, $304 \mathrm{p}$.

DOMINGUEZ JML, ANDRADE ACS, ALMEIDA AB \& BITTENCOURT ACSP. 2009. The Holocene Barrier Strandplains of the State of Bahia. In: DILLENBURG SR \& HESP PA. Geology and Geomorphology of Holocene coastal barriers of Brazil. Springer-Verlag Berlin Heidelberg, 377 p.

FLO0D RD. 1980. Deep sea sedimentary morphology: modelling and interpretation of echo-sounding profiles. Mar. Geol., 38: 77-92.

GHIGNONE JI. 1979. Geologia dos Sedimentos Fanerozoicos do Estado da Bahia. In: CAVALCANTI SS. 2006. Quantificação dos recursos hídricos subterrâneos do aquífero recôncavo na bacia do rio Capivara. Tese de Doutorado em Geofísica. Instituto de Geociências, Universidade Federal da Bahia. Salvador - Bahia, 121 p.

LESSA GC \& DIAS KA. 2009. Distribuição espacial das litofácies de fundo da Baía de Todos os Santos. Quaternary and Environmental Geosciences, 1(2): 84-97.

LIMA OAL. 1999. Caracterização hidráulica e padrões de poluição no aquífero Recôncavo na região de Camaçari - Dias D’Ávila, Tese Prof. Titular, Universidade Federal da Bahia, Salvador. 123 p.

LIMA GMP. 2007. Caracterização sedimentológica e dos padrões de circulação e mistura do estuário do rio Jacuípe - Litoral Norte do Estado da Bahia. Dissertação de Mestrado em Geologia. Instituto de Geociências, Universidade Federal da Bahia. Salvador - Bahia, 137 p.

LIMA GMP \& LESSA GC. 2001. The Fresh-Water Discharge in Todos os Santos Bay (BA) and its significance to the General Water Circulation. Revista Pesquisas em Geociências, Universidade Federal do Rio Grande do Sul-RS, 28(2): 85-97.

LIMA OAL \& SHARMA MM. 1990. A grain conductivity approach to shaly sandstones. Geophysics, 55: 1347-1356.

LIMA CCU, VILAS BOAS GS \& BEZERRA FHR. 2006. Faciologia e análise tectônica preliminar da formação Barreiras no litoral sul do estado da Bahia, Brasil. Geol. USP Sér. Cient., São Paulo, 6: 71-80.

LIMA GMP, VILAS BOAS GS, COSTA AB \& ARGOLLO RM. 2011. Taxas de sedimentação recentes provenientes dos métodos $\mathrm{Cs}^{137}$ e $\mathrm{Pb}^{210}$ e estimativa de preenchimento do estuário Jacuípe, Bahia, Brasil. Revista Brasileira de Geociências, 41(1): 44-55.

MAGNAVITA LP. 1992. Geometry and kinematics of the RecôncavoTucano-Jatobá Rift, NE-Brazil. In: BUENO GV. 2004. Diacronismo de eventos no rifte Sul-Atlântico. B. Geoci. Petrobras, 12: 203-229.

MAGNAVITA LP, SILVA RR \& SANCHES CP. 2005. Guia de campo da Bacia do Recôncavo, NE do Brasil. Boletim de Geociências da Petrobras, 13: 301-334.

MARTIN L, BITTENCOURT ACSP, VILAS BOAS GS \& FLEXOR JM. 1980. Texto explicativo para o mapa geológico do quaternário costeiro do estado da Bahia. Escala 1:250.000. CPM/SME. Salvador, 60 p.
MARTIN L, BITTENCOURT ACSP \& VILAS BOAS GS. 1982. Primeira ocorrência de corais pleistocênicos da costa brasileira: datação do máximo da penúltima transgressão. Ciências da Terra, 3: 16-17.

MARTIN L, FLEXOR JM, BITTENCOURT ACSP \& DOMINGUEZ JML. 1986. Neotectonic movements on a passive continental margin: Salvador region, Brazil. Neotectonics, 1: 87-103.

MARTIN L, DOMINGUEZ JML \& BITTENCOURT ACSP. 2003. Fluctuating Holocene sea levels in eastern and southeastern Brazil: Evidence from multiple fossil and geometric indicators. Journal of Coasta Research, 19: 101-124.

MILANI EJ. 1987. Aspectos da evolução tectônica das bacias do Recôncavo e Tucano Sul, Bahia, Brasil. Ciência Técnica Petróleo, 18: $61 \mathrm{p}$.

MILLER KG, KOMINZ MA, BROWNING JV, WRIGHT JD, MOUNTAIN GS, KATZ ME, SUGARMAN PJ, CRAMER BS, CHRISTIE-BLICK N \& PEKAR SF. 2005. The phanerozoic record of global sea-level change. Science, 310: 1293-1298.

MORAIS NETO JM, HEGARTY KA \& KARNER GD. 2006. Abordagem preliminar sobre paleotemperatura e evolução do relevo da Bacia do Araripe, Nordeste do Brasil, a partir da análise de traços de fissão em apatita. Boletim de Geociências da Petrobras, 14: 113-119.

PORSANI JL, BORGES WR, ELIS VR, DIOGO LA, HIODO FY, MARRANO A \& BIRELLI CA. 2004. Investigações geofísicas de superfície e de poço no sítio controlado de geofísica rasa do IAG-USP. Revista Brasileira de Geofísica, 22(3): 245-258.

QUARESMA VS, DIAS GTM \& BAPTISTA NETO JA. 2000. Caracterização da ocorrência de padrões de sonar de varredura lateral e sísmica de alta frequência (3,5 e 7,0 kHz) na porção sul da Baía de Guanabara-RJ. Revista Brasileira de Geofísica, 18(2): 201-214.

SANTOS CPL. 2003. Análise geofísica das características hidráulicas da falha de Salvador na região de Arembepe-Ba. Dissertação de Mestrado em Geofísica. Instituto de Geociências, Universidade Federal da Bahia. Salvador - Bahia, 93 p.

TURNER JP, GREEN PF, HOLFORD SP \& LAWRENCE SR. 2008. Thermal history of the Rio Muni (West Africa) - NE Brazil margins during continental breakup. Earth and Planetary Science Letters, 270: 354-367.

VILAS BOAS GS, SAMPAIO FJ \& PEREIRA AMS. 2001. The Barreiras Group in the northeastern coast of the State of Bahia, Brazil: depositional mechanisms and processes. Anais da Academia Brasileira de Ciências, 73(3): 417-427.

WESCHENFELDER J, CORRÊA ICS, TOLDO Jr EE \& BAITELLI R. 2008. Paleocanais como indicativo de eventos regressivos quaternários do nível do mar no sul do Brasil. Revista Brasileira de Geofísica, 26(3): 367-375. 


\section{NOTAS SOBRE OS AUTORES}

Geraldo Marcelo Pereira Lima. Professor Adjunto do Instituto de Geociências da Universidade Federal da Bahia (UFBA). Mestre e Doutor em Geologia pela UFBA. Pesquisador do Núcleo de Geologia Básica (NGB-UFBA) e colaborador do Centro de Pesquisa em Geofísica e Geologia (CPGG-UFBA). Tem experiência na área de Geociências, atuando principalmente em sedimentologia e geomorfologia tropical. Pesquisa voltada para taxas de denudação, taxas de sedimentação, preenchimento sedimentar e espaço de acomodação.

Geraldo da Silva Vilas Boas. Graduado em Geologia pela Universidade Federal da Bahia (1966), especialização em Géologie pela Université Louis Pasteur de Strasbourg (1972) e doutorado em Géologie pela Université Louis Pasteur de Strasbourg (1975). Professor Titular do IGE0-UFBA e membro do corpo editorial da Revista Brasileira de Geociências. Áreas de atuação: sedimentologia, rochas sedimentares, evolução dos tabuleiros costeiros e depósitos associados.

Olivar Antônio Lima de Lima. Graduado em Geologia (1967) e Mestre em Geologia Estrutural (1970) pela Universidade Federal do Rio de Janeiro (UFRJ). Doutor em Geofísica (1979) pela UFBA. Pós-Doutorado (1989-1990) no Departamento de Engenharia de Petróleo da Universidade do Texas, Austin. Professor Titular do IGE0UFBA. Áreas de atuação: Aplicação de métodos geofísicos na exploração de água subterrânea, petróleo e problemas ambientais; petrofísica. É sócio da SBGf, SBG e ABAS; e da SEG, EAGE, AGU e SPWLA. 